obtained from the cadmium sulphate solution, using the acetate, formate, or lactate electrolyte. The formate ion also seems to exert a good influence on the deposit, cadmium acetate solution with the formate electrolyte giving satisfactory results even in presence of the alkaline earth metals, and cadmium formate solution with the lactate electrolyte also giving good deposits. It is of interest to observe that the acetate and lactate electrolytes when used alone are not so successful, and the combination is an extremely poor one.

It is clear that other organic electrolytes should be investigated, and that many interesting and valuable relations may be found in the comparison of the nature of the deposits from different electrolytes and from their combinations. It is hoped that this investigation may be continued in this laboratory.

Mount Holyoke College.

SOUTH HADLEY, Mass.

[CONTRibution from the Chemical Laboratory of the University of Ilinots.]

\title{
DETERMINATION OF AMMONIA NITROGEN IN WATER IN THE PRESENCE OF HYDROGEN SULPHIDE.
}

BY EDWARD BARTOW AND B. H. HARRISON,

Received July 4, 1910 .

The tests for free and albuminoid ammonia, since their introduction in 1867, have played an important role in the sanitary examination of drinking-water. They have been criticized because of inaccuracies due to interferences from substances in solution, and it is this phase of the subject that we have been investigating. In the experimental work we have taken the usual precautions to have a uniform rate of distillation, a uniform temperature for Nesslerization, a uniform organic content in comparative tests, all glass apparatus and a room free from ammonia fumes. As an illustration of the necessity for the last precaution we found that 0.036 part per million of ammonia nitrogen was added to a water exposed for 24 hours in the distilling room, which adjoined a room where dogs were kept for experimental work in physiological chemistry, and that 0.566 part per million was added to water in the room where the dogs were kept.

Natural waters sometimes contain substances which may cause interference if these combine with ammonia to prevent its distillation or if they are distilled with the ammonia and interfere with the Nessler test. Of the former class are acids like sulphuric acid, which, as is well known, must be neutralized before distillation. Of the latter class is hydrogen sulphide, which will distil over with the ammonia and will give false results.

We have studied the effect of three substances, calcium acid carbonate. 
magnesium chloride and hydrogen sulphide. Our results indicate that calcium acid carbonate and magnesium chloride in the amounts ordinarily found in natural water do not interfere materially with the determination of free ammonia. Kober ${ }^{1}$ has stated that in the presence of magnesium chloride all the ammonia is not given off. This may be true if the concentration of the magnesium chloride is very high. Our experiments with an amount of magnesium chloride in excess of the amounts found in any of the Illinois water supplies lead us to conclude that the interference is not material.

Hydrogen sulphide, however, interferes with the Nessler test. When the amount of ammonia is large the hydrogen sulphide might be removed by precipitation with a lead or zinc salt and the ammonia determined by direct nesslerization, but if small and it is desirable to distil and nesslerize the distillates, the results are very inaccurate. This is shown in our first test. We added 0.06 part per million of ammonia nitrogen to a water in which $5^{6}$ parts per million of purified hydrogen sulphide gas had been absorbed. Nesslerization after distillation showed 0.082 , 0.2 I 4 and 0.376 part per million of nitrogen when only 0.06 part per million had been taken. A repetition of the experiment gave similar inaccurate results.

The hydrogen sulphide must evidently be prevented from interfering either by distilling it off in the presence of something that will hold the ammonia or in holding it back while the ammonia is being distilled. The use of sulphuric acid to retain the ammonia in the Kjeldahl process led us to try it. To $500 \mathrm{cc}$. of a water containing 20 parts per million of hydrogen sulphide and a known amount of ammonia nitrogen, 5o cc. of normal sulphuric acid was added and roo $\mathrm{cc}$. of water distilled over. The first tube was cloudy and smelled strongly of hydrogen sulphide gas; the second tube was practically clear. $50 \mathrm{cc}$. of a normal solution of sodium hydroxide was then added and $200 \mathrm{cc}$. of water distilled and nesslerized. On the first series with 0.06 part per million taken 0.082 ,

Table 1.--Determination of Ammonia Nitrogen in the Presence of Hydrogen SULPHIDE. RESUlTS IN PARTS PER MILLION.

$\begin{array}{cccc}\text { rotal N found. } & \text { Correction. } & \text { Nitrogen found. } & \text { Nitrogen ta } \\ 0.082 & 0.026 & 0.056 & 0.060 \\ 0.086 & 0.026 & 0.060 & 0.060 \\ 0.082 & 0.026 & 0.056 & 0.060 \\ 0.416 & 0.030 & 0.386 & 0.400 \\ 0.400 & 0.030 & 0.370 & 0.400 \\ 0.136 & 0.020 & 0.116 & 0.120 \\ 0.256 & 0.020 & 0.236 & 0.240 \\ 0.528 & 0.020 & 0.508 & 0.500 \\ 1.040 & 0.020 & 1.020 & 1.000 \\ 2.000 & 0.020 & 1.980 & 2.000\end{array}$

${ }^{1}$ This Jotrnal, 30, 1279-81. 
$0.080,0.078$ and 0.082 part per million was found. This showed the necessity for control tests which were run in succeeding series. The readings with the corrections are shown in Table $I$. The results are sufficiently accurate.

With respect to the holding of the hydrogen sulphide and the distillation of the ammonia, the addition of sodium hydroxide would not be satisfactory as the sodium sulphide formed would hydrolyze and hydrogen sulphide would be found in the distillate.

Phelps, ${ }^{1}$ in discussing the direct nesslerization of sewage, suggests the precipitation of the hydrogen sulphide with lead or zinc acetate. We have tried lead acetate and have compared it "with the sulphuric acid method, as shown in Table II:

TABLE II-Determination of Ammonia Nitrogen by Addition of Strphuric Acid OR LeAd ACETate. Results in PaRTS PER Militon.

$\begin{array}{ccccl}\text { Total N found. } & \text { Correction. } & \text { Nitrogen found. } & \text { Nitrogen taken. } & \begin{array}{c}\text { Method. } \\ 0.090\end{array} \\ 0.029 & 0.06 \mathrm{I} & 0.060 & \text { Sulphuric acid } \\ 0.088 & 0.029 & 0.059 & 0.060 & \text { Sulphuric acid } \\ 0.094 & 0.034 & 0.060 & 0.060 & \text { Sulphuric acid } \\ 0.090 & 0.034 & 0.056 & 0.060 & \text { Sulphuric acid } \\ 0.074 & 0.029 & 0.044 & 0.060 & \text { Lead acetate } \\ 0.056 & 0.029 & 0.027 & 0.060 & \text { Lead acetate } \\ 0.072 & 0.023 & 0.049 & 0.060 & \text { Lead acetate } \\ 0.074 & 0.017 & 0.057 & 0.060 & \text { Control, no } \mathrm{H}_{2} \mathrm{~S} \\ 0.074 & 0.017 & 0.057 & 0.060 & \text { Control, no } \mathrm{H}_{2} \mathrm{~S}\end{array}$

The method with sulphuric acid gives results as accurate as can be obtained when there is no hydrogen sulphide present while the results obtained by the use of lead acetate are low.

In order to determine the effect of the addition of sulphuric acid on the TABle III.-The EFFEct of AdDING Sulphuric Acid on the AMount of Ammonia ObTained. Results in Parts per Milition.

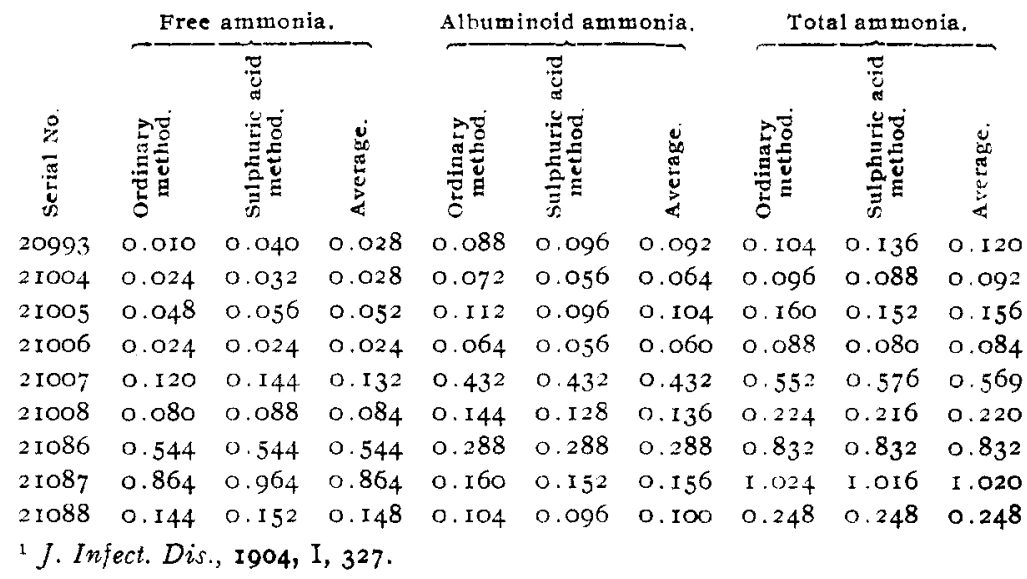


so-called albuminoid ammonia, a series of waters were analyzed with and without the addition of sulphuric acid. The results of the analyses of nine typical Illinois waters as given in Table III show that the sulphuric acid has no appreciable effect on the amount of ammonia obtained. While the results are not identical, the variations are within the limits of experimental error.

URBANA, ILL.

\section{THE COMPOSITION OF SOME GREEK VASES.}

BY WILLIAM Foster.

Received July r8, igro.

The purpose of this article is to give an account of some chemical tests made in order to determine the nature and composition of the black glaze of the black-figured and red-figured Attic styles and the red glaze of the Mycenaean style of vases.

This investigation was undertaken at the request of my colleague, Dr. O. S. Tonks, who is interested in Greek pottery from the standpoint of an archaeologist.

Guided by the results of these chemical tests, Tonks has confirmed some of the observations by synthesis, a partial account of which has already been published. ${ }^{1}$

\section{Experiments with the Black Glaze.}

(I) Historical Introduction.-The nature and composition of the fine black glaze on Greek pottery has been a subject of discussion and more or less speculation for many years. As far back as $176 \mathrm{r}$ Caylus, ${ }^{2}$ as a result of his investigations, claimed that the glaze was made up of a ferruginous earth, which he classified as manganese. He claimed that this substance baked red, but could be rendered black by an admixture of color, or other earths.

According to Blümner, ${ }^{3}$ some later investigators have advanced theories that the materials of the glaze might be graphite and magnesia, that the glaze is made up of an earth but not a metal, and that a combination of the oxides of iron and manganese may have produced the black. Rlümner claimed, however, that the real nature of the black color had not been finally determined.

Of the earlier experiments carried out with a view to discover the composition of the glaze, perhaps those of Salvétat," at the Sèvres potteries, are the most worthy of consideration. While Salvétat, in reporting

1 Tonks, Am. J. Archaeology, 12, 4 I7 (1908).

2 Recueil d' Antiquités, r, 86-7.

3 "Technologie und Terminologie der Gewerbe und Künste bei Griechen und Römern, II, pp. 74 ff. The work done up to 1879 is here summarized.

"Brongniart, "Traité des Arts Ceramiques," I, pp. 549-52. 